\title{
A Single-Center Retrospective and Descriptive Study of Hepatobiliary and Pancreatic Surgical Oncology during the COVID-19 Epidemic
}

\section{Zhi-Ming Zhao}

Chinese PLA General Hospital

\section{Xiu-Ping Zhang}

PLA General Hospital

\section{Shuai $X u$}

Chinese PLA General Hospital

\section{Xiang-Long Tan}

PLA Army General Hospital

\section{Xuan Zhang}

Chinese PLA General Hospital

Ming-Gen $\mathrm{Hu}$

PLA General Hospital

Cheng-Gang Li

Chinese PLA General Hospital

\section{Yuan-Xing Gao}

Chinese PLA General Hospital

Guo-Dong Zhao

PLA Army General Hospital

Rong Liu ( $\square$ liurong301@126.com )

Chinese People's Liberation Army(PLA) General Hospital

\section{Research}

Keywords: COVID-19 epidemic, Hepatobiliary pancreatic tumor, Robotic Surgery, Retrospective and descriptive study

Posted Date: July 16th, 2020

DOI: https://doi.org/10.21203/rs.3.rs-40427/v1

License: (c) (1) This work is licensed under a Creative Commons Attribution 4.0 International License. Read Full License 


\section{Abstract}

Objective: In the battle against COVID-19, most medical resources in China have been directed to infected patients in Wuhan. Thus, patients with hepatobiliary pancreatic tumors who are not suffering from COVID-19 are often not given timely and effective anti-cancer treatments. In this study, we aimed to describe clinical characteristics, treatment, and outcomes of patients with hepatobiliary and pancreatic oncology from our department, which retained normal working during the COVID-19 epidemic. We also sought to formulate a set of standardized hospitalization and treatment processes.

Methods: A retrospective and descriptive study was conducted involving patients hospitalized from February 1, 2020, to February 29, 2020 (Return to work after the Spring Festival), at our Department of Hepatobiliary and Pancreatic Surgical Oncology.

Results: The study included 92 patients from 12 provinces in the north of China who underwent surgical resection at our Department of Hepatobiliary and Pancreatic Surgical Oncology during the COVID-19 epidemic. Robotic surgery was performed on $82 \%$ (75/92) of patients, while the rest underwent laparoscopic (2/92) and open surgery (15/92). Eighty-six patients had malignant tumor, and six had emergency benign diseases. Only five patients had severe pancreatic fistula, and three had biliary fistula after operation.

Conclusions: The standardized hospitalization and treatment processes described in this study could prevent cross-infection of patients and still ensure timely treatment of patients with hepatobiliary and pancreatic cancers. These study findings will guide the management of surgical oncology departments and treatment of patients with hepatobiliary and pancreatic oncology during serious epidemics.

\section{Introduction}

Coronaviruses are enveloped, non-segmented, positive-sense RNA viruses broadly distributed in humans and other mammals. ${ }^{1}$ Although most human coronavirus infections are mild, epidemics of the severe acute respiratory syndrome coronavirus (SARS-CoV) and Middle East respiratory syndrome coronavirus (MERS-CoV) together caused more than 10,000 cases in the past two decades, with mortality rates of $10 \%$ for SARS-CoV and $37 \%$ for MERS-CoV. ${ }^{2-4}$ Wuhan, the capital of Hubei province in China, is investigating an outbreak of atypical pneumonia caused by the zoonotic severe acute respiratory syndrome coronavirus 2 or the novel 2019 coronavirus (COVID-19). ${ }^{5}$ In the early stages of this pneumonia, severe acute respiratory infection symptoms occur, with some patients rapidly developing acute respiratory distress syndrome, acute respiratory failure, and other serious complications. The National Health Commission of China has developed a case-definition system to facilitate the classification of patients (panel). To mitigate the spread of the virus, the Chinese Government has progressively implemented metropolitan-wide quarantine of Wuhan and several nearby cities since Jan $24,2020 .{ }^{6}$ In the battle against COVID-19, most medical resources have been directed to infected patients in Wuhan, resulting in many hospitals being closed or open to emergencies only. Thus, many patients 
with malignancies were denied curative therapies, leading to an increase in non-infectious deaths during isolation at home. Patients with cancer who were not infected with COVID-19 were denied timely and effective anti-cancer treatments.

Hepatobiliary pancreatic tumors are one of the most common cancers and the leading cause of cancerrelated death worldwide. ${ }^{7}$ Patients with liver, gallbladder, or pancreatic cancer have fast progression and poor prognosis. With recent improvements in surgical techniques (robotic and laparoscopic surgery), ${ }^{8,9}$ medical care, and non-surgical treatment (radiotherapy, chemotherapy, and targeted therapy), treatment modalities in these patients vary greatly among different institutions. ${ }^{10,11}$ Clearly, timely and effective treatments should be given to these patients. Therefore, in light of the COVID-19 epidemic, clinicians must consider how to reasonably allocate limited medical resources and establish a balanced medical security system to ensure that patients with hepatobiliary pancreatic tumor receive proper treatment.

Research has focused increasingly on patients infected with COVID-19, with the epidemiology and clinical features of patients with confirmed $2019 \mathrm{nCoV}$ pneumonia being explored in depth. ${ }^{12-14}$ However, few studies have investigated the clinical treatment and management of patients with hepatobiliary and pancreatic oncology during the COVID-19 epidemic and clinical approaches taken by departments of hepatobiliary and pancreatic surgical oncology.

Therefore, we aimed to describe clinical, laboratory, and radiological characteristics, as well as treatment and outcomes of patients with hepatobiliary and pancreatic oncology treated in our department, which maintained normal working hours during the COVID-19 epidemic. In addition, as hepatobiliary surgeons, we performed timely treatment of patients with hepatobiliopancreatic tumors, avoiding cross-infection of patients and formulating a standardized treatment process. We hope our study findings will guide the management of surgical oncology departments and treatment of patients with hepatobiliary and pancreatic oncology during serious epidemics.

\section{Methods}

\section{Admission process during COVID-19 epidemic}

Our hospital did not completely halt services to some patients who needed to visit the Hepatobiliary and Pancreatic Surgical Oncology outpatient department during the COVID-19 outbreak, nor did we cease hepatobiliary and pancreatic surgery, although we did limit the department to emergency operations and elective surgeries for patients with hepatobiliary and pancreatic cancers. To meet the medical requirements and reduce the flow of patients to the hepatobiliary pancreatic surgery clinic, we began free online and telephone hepatobiliary and pancreatic consultation. Patients made an advanced appointment to receive this medical service. People entering the outpatient and inpatient buildings were required to wear masks and had their body temperature checked by professionals wearing tight protective clothing. At the entrance to the building, anyone with a fever (body temperature $\geq 37.3^{\circ} \mathrm{C}$ ), a travel history to Hubei in the last 2 weeks, clear contact with Hubei residents in the last 2 weeks, or contact with people 
having fever were sent directly to the fever clinic for screening; those who had been exposed were quarantined for 2 weeks, while those with potential exposure were asked to quarantine themselves at home for 2 weeks. At the hepatobiliary pancreatic surgery clinic, patients were not allowed to take off their masks. Doctors were required to wear masks, surgical caps, protective suits, gloves, and goggles at work, and to take off their protective equipment only after their work in a designated disposal area.

All patients were first isolated in the local community for 14 days. When they were admitted to the hospital, they made an appointment for medical treatment in the Department of Hepatobiliary and Pancreatic Surgical Oncology. A chest plain scan computed tomography (CT) was performed in the outpatient department. Those with normal inspection results were then issued a hospital admission form. If the patients had fever symptoms, they were required to have a throat swab examination. After admission, they were isolated in the transitional ward for 3 days; they then underwent preoperative examination and surgery.

\section{Study population}

A retrospective study was conducted on patients hospitalized from February 1, 2020, to February 29, 2020 (Return to work after the Spring Festival), at the Department of Hepatobiliary and Pancreatic Surgical Oncology, during the COVID-19 epidemic. Clinical and pathological data of these patients were retrospectively analyzed. The present study was approved by our Institutional Ethics Committee. Informed consent was obtained from all patients for their data to be used for research. In addition, this study included patients' basic information gathered between 2017 and 2019.

\section{Inclusion and exclusion criteria}

The inclusion criteria were patients with hepatobiliary and pancreatic cancer with: (1) good basic state and liver function (Child-Pugh score of A or B7 $\leq 7$ ); (2) complete preoperative serological data and contrast-enhanced CT or MRI of the abdomen; (3) surgical resection with no residual tumors left, based on both gross inspection and histological examination of the resection specimens; (4) histopathological diagnosis of hepatobiliary or pancreatic cancer; (5) no macrovascular invasion or extrahepatic metastasis; and (6) complete pathological and clinical data during follow-up. The exclusion criteria were: (1) a history of other cancers; and (2) incomplete clinical data.

\section{Preoperative and postoperative investigations}

Routine preoperative investigations included imaging and serological tests. All patients underwent a standard hepatobiliary and pancreatic surgery imaging protocol that included abdominal ultrasonography, contrast-enhanced MRI and/or CT scan of the abdomen, and plain radiography or noncontrast CT scan of the chest. All radiological examinations were reviewed by two experienced radiologists. Routine preoperative laboratory investigations included complete blood counts, liver and renal function tests, and tumor marker level. The coagulability state and infection index were obtained before surgery. Routine postoperative investigations included histopathology and immunohistochemical studies. Other pathological indexes used in this study included maximum tumor diameter, number of 
tumors, and tumor encapsulation. Histopathological evaluations were performed by two independent and experienced pathologists who were blinded to the clinical data.

\section{Treatment}

All patients were assessed by a multidisciplinary team of experienced liver surgeons, oncologists, radiologists, and hepatologists at our hospital. Surgical resection was the treatment of choice if the disease was resectable. Surgical procedures have been reported previously, including open surgery, laparoscopic surgery, and robotic surgery.

\section{Follow-up}

Patients who underwent surgery were followed up once every day. In particular, their body temperature, infection index, and surgical related complications were recorded. Surgical complications and death were recorded during the postoperative hospital stay. This study was censored on March 1, 2020.

\section{Statistical analysis}

To compare baseline variables, the Student's t-test was used for continuous variables and the $\chi 2$ test for categorical variables. Survival curves and univariate analyses were conducted using the Kaplan-Meier method, and differences were analyzed using the log-rank test. Prognostic factors that were significant on univariate analysis $(P<0.05)$ were subjected to multivariate analysis using the Cox proportional hazards regression model. All reported P-values were two-sided. A significance level of 0.05 was applied throughout. Statistical analyses were performed using the R statistical package, Version 3.4.3 (R Development Team, Vienna, Austria).

\section{Results}

\section{Changes of disease spectrum}

Our hospital treated 92 patients from 12 provinces in the north of China during the COVID-19 epidemic (Fig. 1). In the time period from 2017 to 2020 , the proportion of patients with malignant tumors increased significantly, even though the total number of surgical patients decreased (Fig. 2). During the COVID-19 epidemic, limited medical resources were directed to patients with malignant tumors. The use of robotic surgery also increased, which indicated that minimally invasive surgery can accelerate the recovery of patients after surgery (Fig. 3).

\section{Patient characteristics}

All 92 patients with hepatobiliary pancreatic diseases in this study were hospitalized during the outbreak from February 1, 2020, to February 29, 2020 (after the Spring Festival in China). They were divided into two groups according to their gender ( 66 men; 26 women). Baseline characteristics of all patients with hepatocellular carcinoma are detailed in Table 1. All patients had a normal body temperature $\left(<37.3^{\circ} \mathrm{C}\right)$ before surgery. Preoperative chest CT was normal in $90.2 \%$ of patients; $6.5 \%$ had cardiopulmonary 
changes, all of whom were elderly, and one patient had bacterial pneumonia, old tuberculosis, or solid pulmonary nodule. None of the variables listed above showed any significant difference between the groups, except for weight and height (Table 1). 
Table 1

The clinical features of patients in our Department of Hepatobiliary and Pancreatic Surgical Oncology ( $=92$ )

\begin{tabular}{|c|c|c|c|c|}
\hline Variables & $\begin{array}{l}\text { Total } \\
(\mathrm{N}=92)\end{array}$ & $\begin{array}{l}\text { Male } \\
(\mathrm{N}=66)\end{array}$ & $\begin{array}{l}\text { Female } \\
(\mathrm{N}=26)\end{array}$ & $\begin{array}{l}\mathrm{P}- \\
\text { value }\end{array}$ \\
\hline Age & $58.21 \pm 11.59$ & $58.22 \pm 11.282$ & $58.74 \pm 11.061$ & 0.896 \\
\hline$\leqq 50$ & $21(22.8 \%)$ & $15(22.7 \%)$ & $6(23.1 \%)$ & \multirow[t]{2}{*}{0.971} \\
\hline$>50$ & 71(77.2\%) & $51(77.3 \%)$ & $20(76.9 \%)$ & \\
\hline Temperature & $36.58 \pm 0.29$ & $36.61 \pm 0.28$ & $36.53 \pm 0.30$ & 0.245 \\
\hline$<37.3^{\circ} \mathrm{C}$ & $92(100 \%)$ & $66(100 \%)$ & $26(100 \%)$ & \\
\hline$\geq 37.3^{\circ} \mathrm{C}$ & $0(0 \%)$ & $0(0 \%)$ & $0(0 \%)$ & \\
\hline $\operatorname{RBC}\left(10^{\wedge} 12 / L\right)$ & $4.03 \pm 0.65$ & $4.07 \pm 0.72$ & $3.92 \pm 0.44$ & 0.209 \\
\hline$<3.5$ & 16(17.4\%) & $11(16.7 \%)$ & $5(19.2 \%)$ & \multirow[t]{3}{*}{0.770} \\
\hline $3.5 \sim 5.5$ & $76(82.6 \%)$ & $55(83.3 \%)$ & $21(80.8 \%)$ & \\
\hline$>5.5$ & $0(0 \%)$ & $0(0 \%)$ & $0(0 \%)$ & \\
\hline WBC (10^9/L) & $6.34 \pm 2.78$ & $6.01 \pm 1.81$ & $7.17 \pm 4.30$ & 0.195 \\
\hline$<4$ & 10(10.9\%) & $6(9.1 \%)$ & $4(15.4 \%)$ & \multirow[t]{3}{*}{0.064} \\
\hline $4 \sim 10$ & $78(84.8 \%)$ & $59(89.4 \%)$ & 19(73.1\%) & \\
\hline$>10$ & $4(4.3 \%)$ & $1(1.5 \%)$ & $3(11.5)$ & \\
\hline Neutrophil proportion & $0.62 \pm 0.11$ & $0.62 \pm 0.09$ & $0.63 \pm 0.15$ & 0.820 \\
\hline$<0.5$ & $13(14.1 \%)$ & $8(12.1 \%)$ & $5(19.2 \%)$ & \multirow[t]{3}{*}{0.208} \\
\hline $0.5 \sim 0.7$ & $62(67.4 \%)$ & $48(72.7 \%)$ & $14(53.8 \%)$ & \\
\hline$>0.7$ & 17(18.5\%) & $10(15.2 \%)$ & $7(26.9 \%)$ & \\
\hline Lymphocyte proportion & $0.27 \pm 0.10$ & $0.27 \pm 0.09$ & $0.28 \pm 0.12$ & 0.569 \\
\hline$<0.2$ & 19(20.7\%) & 13(19.7\%) & $6(23.1 \%)$ & \multirow[t]{3}{*}{0.456} \\
\hline $0.2 \sim 0.4$ & $61(66.3 \%)$ & $46(69.7 \%)$ & $15(57.7 \%)$ & \\
\hline$>0.4$ & 12(13.0\%) & $7(10.6 \%)$ & $5(19.2 \%)$ & \\
\hline CRP (mg/L) & $3.68 \pm 3.54$ & $3.49 \pm 3.51$ & $4.15 \pm 3.66$ & 0.451 \\
\hline$\leq 10$ & $85(92.4 \%)$ & $61(92.4 \%)$ & 24(92.3\%) & \multirow[t]{2}{*}{1.000} \\
\hline$>10$ & $7(7.6 \%)$ & $5(7.6 \%)$ & 2(7.7\%) & \\
\hline
\end{tabular}




\begin{tabular}{|c|c|c|c|c|}
\hline Variables & $\begin{array}{l}\text { Total } \\
(\mathrm{N}=92)\end{array}$ & $\begin{array}{l}\text { Male } \\
(\mathrm{N}=66)\end{array}$ & $\begin{array}{l}\text { Female } \\
(\mathrm{N}=26)\end{array}$ & $\begin{array}{l}\mathrm{P}- \\
\text { value }\end{array}$ \\
\hline AST(U/L) & $47.29 \pm 46.88$ & $46.38 \pm 44.60$ & $49.62 \pm 53.09$ & 0.767 \\
\hline$\leq 35$ & $52(56.5 \%)$ & $37(56.1 \%)$ & $15(57.7 \%)$ & \multirow[t]{2}{*}{0.887} \\
\hline$>35$ & $40(43.5 \%)$ & $29(43.9 \%)$ & $11(42.3 \%)$ & \\
\hline ALT(U/L) & $62.25 \pm 80.89$ & $68.50 \pm 91.80$ & $46.39 \pm 39.25$ & 0.271 \\
\hline$\leq 40$ & $46(50.0 \%)$ & $32(48.5 \%)$ & $14(53.8 \%)$ & \multirow[t]{2}{*}{0.643} \\
\hline$>40$ & $46(50.0 \%)$ & $34(51.5 \%)$ & $12(46.2 \%)$ & \\
\hline CR (umol/L) & $72.14 \pm 18.11$ & $74.43 \pm 17.95$ & $66.34 \pm 17.54$ & 0.053 \\
\hline$\leq 105$ & $90(97.8 \%)$ & $64(97.0 \%)$ & $26(100.0 \%)$ & \multirow[t]{2}{*}{1.000} \\
\hline$\otimes 105$ & $2(2.2 \%)$ & $2(3.0 \%)$ & $0(0 \%)$ & \\
\hline BUN (mmol/L) & $6.00 \pm 10.03$ & $6.53 \pm 11.75$ & $4.64 \pm 2.05$ & 0.036 \\
\hline$\leq 7.1$ & $81(88.0 \%)$ & $58(87.9 \%)$ & $23(88.5 \%)$ & \multirow[t]{2}{*}{1.000} \\
\hline$\otimes 7.1$ & $11(12.0 \%)$ & $8(12.1 \%)$ & $3(11.5 \%)$ & \\
\hline \multicolumn{5}{|l|}{ Chest CT } \\
\hline Normal & $83(90.2 \%)$ & $58(87.9 \%)$ & $25(96.2 \%)$ & \multirow[t]{5}{*}{0.879} \\
\hline $\begin{array}{l}\text { Cardiopulmonary changes in the } \\
\text { elderly }\end{array}$ & $6(6.5 \%)$ & $5(7.6 \%)$ & $1(3.8 \%)$ & \\
\hline Bacterial pneumonia & $1(1.1 \%)$ & $1(1.5 \%)$ & $0(0.0 \%)$ & \\
\hline Old tuberculosis & $1(1.1 \%)$ & $1(1.5 \%)$ & $0(0.0 \%)$ & \\
\hline Solid pulmonary nodule & $1(1.1 \% 0$ & $1(1.5 \%)$ & $0(0.0 \%)$ & \\
\hline \multicolumn{5}{|l|}{ Previous surgical history } \\
\hline yes & $27(29.3 \%)$ & $15(22.7 \%)$ & $12(46.2 \%)$ & \multirow[t]{2}{*}{0.026} \\
\hline no & $65(70.7 \%)$ & $51(77.3 \%)$ & $14(53.8 \%)$ & \\
\hline Weight (kg) & $68.60 \pm 11.11$ & $70.71 \pm 10.92$ & $63.25 \pm 9.89$ & 0.003 \\
\hline Height (cm) & $168.75 \pm 6.80$ & $171.67 \pm 4.98$ & $161.35 \pm 4.95$ & 0.000 \\
\hline $\mathrm{BMI}\left(\mathrm{kg} / \mathrm{m}^{2}\right)$ & $24.08 \pm 3.59$ & $23.98 \pm 3.50$ & $24.32 \pm 3.86$ & 0.685 \\
\hline Preoperative time (d) & $7.25 \pm 3.41$ & $7.43 \pm 3.63$ & $6.79 \pm 2.77$ & 0.420 \\
\hline Postoperative time (d) & $8.33 \pm 3.25$ & $8.69 \pm 3.42$ & $7.43 \pm 2.65$ & 0.095 \\
\hline
\end{tabular}




\begin{tabular}{|c|c|c|c|c|}
\hline Variables & $\begin{array}{l}\text { Total } \\
(\mathrm{N}=92)\end{array}$ & $\begin{array}{l}\text { Male } \\
(\mathrm{N}=66)\end{array}$ & $\begin{array}{l}\text { Female } \\
(\mathrm{N}=26)\end{array}$ & $\begin{array}{l}\mathrm{P}- \\
\text { value }\end{array}$ \\
\hline Time in hospital (d) & $15.58 \pm 5.25$ & $16.12 \pm 5.51$ & $14.22 \pm 4.30$ & 0.120 \\
\hline Intraoperative hemorrhage (ml) & $190.39 \pm 83.24$ & $196.76 \pm 84.42$ & $174.23 \pm 79.44$ & 0.245 \\
\hline Hepatectomy & $\begin{array}{l}143.93 \pm 65.06 \\
(n=28)\end{array}$ & $\begin{array}{l}147.14 \pm 62.46 \\
(n=21)\end{array}$ & $\begin{array}{l}134.29 \pm 76.78 \\
(n=7)\end{array}$ & 0.659 \\
\hline $\begin{array}{l}\text { Radical resection of hilar } \\
\text { cholangiocarcinoma }\end{array}$ & $\begin{array}{l}215.00 \pm 63.03 \\
(n=12)\end{array}$ & $\begin{array}{l}226.25 \pm 60.93 \\
(n=8)\end{array}$ & $\begin{array}{l}192.50 \pm 69.94 \\
(n=4)\end{array}$ & 0.408 \\
\hline Radical cholecystectomy & $\begin{array}{l}200.00 \pm 50.00 \\
(n=3)\end{array}$ & $\begin{array}{l}200.00 \pm 50.00 \\
(n=3)\end{array}$ & 0 & \\
\hline PD & $\begin{array}{l}267.42 \pm 58.82 \\
(n=31)\end{array}$ & $\begin{array}{l}266.40 \pm 59.36 \\
(n=25)\end{array}$ & $\begin{array}{l}271.67 \pm 61.78 \\
(n=6)\end{array}$ & 0.848 \\
\hline RAMPS & $\begin{array}{l}106.15 \pm 27.25 \\
(n=12)\end{array}$ & $\begin{array}{l}97.50 \pm 31.51(\mathrm{n} \\
=7)\end{array}$ & $\begin{array}{l}120.00 \pm 10.00 \\
(n=5)\end{array}$ & 0.155 \\
\hline Pancreatic tumor enucleation & $50(n=1)$ & $50(n=1)$ & 0 & \\
\hline Others & $\begin{array}{l}116.00 \pm 33.62 \\
(n=5)\end{array}$ & $140.00(n=1)$ & $\begin{array}{l}110.00 \pm 35.59 \\
(n=4)\end{array}$ & 0.506 \\
\hline Operation time (min) & $193.87 \pm 49.31$ & $197.00 \pm 52.86$ & $185.92 \pm 38.66$ & 0.272 \\
\hline Hepatectomy & $\begin{array}{l}173.00 \pm 46.53 \\
(n=28)\end{array}$ & $\begin{array}{l}172.90 \pm 53.49 \\
(n=21)\end{array}$ & $\begin{array}{l}173.29 \pm 14.33 \\
(n=7)\end{array}$ & 0.977 \\
\hline $\begin{array}{l}\text { Radical resection of hilar } \\
\text { cholangiocarcinoma }\end{array}$ & $\begin{array}{l}218.92 \pm 54.85 \\
(n=12)\end{array}$ & $\begin{array}{l}206.50 \pm 45.07 \\
(n=8)\end{array}$ & $\begin{array}{l}243.75 \pm 71.12 \\
(n=4)\end{array}$ & 0.288 \\
\hline Radical cholecystectomy & $\begin{array}{l}239.33 \pm 35.45 \\
(n=3)\end{array}$ & $\begin{array}{l}239.33 \pm 35.45 \\
(n=3)\end{array}$ & 0 & \\
\hline PD & $\begin{array}{l}220.52 \pm 39.95 \\
(n=31)\end{array}$ & $\begin{array}{l}218.52 \pm 39.62 \\
(n=25)\end{array}$ & $\begin{array}{l}228.83 \pm 44.01 \\
(n=6)\end{array}$ & 0.579 \\
\hline RAMPS & $\begin{array}{l}198.69 \pm 25.88 \\
(n=12)\end{array}$ & $\begin{array}{l}209.00 \pm 25.96 \\
(n=7)\end{array}$ & $\begin{array}{l}182.20 \pm 16.67 \\
(n=5)\end{array}$ & 0.066 \\
\hline Pancreatic tumor enucleation & $195(n=1)$ & $195(n=1)$ & 0 & \\
\hline Others & $\begin{array}{l}104.20 \pm 32.74 \\
(n=5)\end{array}$ & $134.00(n=1)$ & $\begin{array}{l}96.75 \pm 32.55 \\
(n=4)\end{array}$ & 0.381 \\
\hline
\end{tabular}

\section{Operative characteristics}

During the COVID-19 epidemic, $82 \%$ of the patients (75/92) underwent robotic surgery, while the rest were treated using laparoscopic (2/92) or open (15/92) surgery. Operations performed in February 2020 included partial hepatectomy, resection of hilar cholangiocarcinoma, pancreaticoduodenectomy, distal 
pancreatic resection, and others (including benign and malignant cholecystectomy). All details are shown in Table 2.

Table 2

Operations carried out during February 2020 in our Department of Hepatobiliary and Pancreatic Surgical Oncology $(n=92)$

\begin{tabular}{|llll|}
\hline Operation & \multicolumn{2}{l}{ Surgical procedures } \\
\cline { 2 - 4 } & Robotic & Laparoscopic & Open \\
\hline Partial hepatectomy & 16 & 0 & 1 \\
\hline Hemihepatectomy & 7 & 0 & 3 \\
\hline Middle hepatectomy & 1 & 0 & 0 \\
\hline Radical resection of hilar cholangiocarcinoma & 10 & 0 & 2 \\
\hline Radical cholecystectomy & 3 & 0 & 0 \\
\hline PD & 26 & 0 & 5 \\
\hline RAMPS & 12 & 0 & 0 \\
\hline Pancreatic tumor enucleation & 1 & 0 & 0 \\
\hline Others & 1 & 2 & $13(14.1 \%)$ \\
\hline Summary (\%) & 77 (83.7\%) & 2 (2.2\%) \\
\hline $\begin{array}{l}\text { Abbreviation: PD: Pancreaticoduodenectomy; RAMPS: Radical antegrade modular } \\
\text { pancreatosplenectomy. }\end{array}$ & & \\
\hline
\end{tabular}

\section{Pathological characteristics}

Among all 92 patients, 86 had malignant tumor and six had benign tumor. Pathological results were pancreatic malignant tumor, cholangiocarcinoma, hepatic carcinoma, periampullary carcinoma, and acute benign diseases. All details are shown in Table 3. 
Table 3

The pathology results of patients in our Department of Hepatobiliary and Pancreatic Surgical Oncology

\begin{tabular}{|llll|}
\hline Pathology results & Subtotal & Ratio \\
\hline Pancreatic head carcinoma & Pancreatic malignant tumor (25) & 11 & $44.0 \%$ \\
\hline Distal pancreatic cancer & & 12 & $48.0 \%$ \\
\hline Insulinoma of the pancreatic body & & 1 & $4.0 \%$ \\
\hline The pancreatic head IPMN & & 1 & $4.0 \%$ \\
\hline Carcinoma of the lower middle bile duct & Cholangiocarcinoma (28) & 13 & $46.4 \%$ \\
\hline Hilar cholangiocarcinoma & & 12 & $42.9 \%$ \\
\hline Carcinoma of gallbladder & & 3 & $10.7 \%$ \\
\hline Hepatic metastatic carcinoma & Malignant tumors of the liver(27) & 9 & $33.3 \%$ \\
\hline Primary liver cancer & & 18 & $66.7 \%$ \\
\hline Periampullary carcinoma & Periampullary carcinoma (6) & 6 & $100.0 \%$ \\
\hline Hepatic echinococcosis & Benign diseases (6) & 1 & $16.7 \%$ \\
\hline Gallstone, acute cholecystitis & & 4 & $66.7 \%$ \\
\hline Bile - intestinal anastomosis stenosis & & 1 & $16.7 \%$ \\
\hline Summary & Malignant & 86 & $93.5 \%$ \\
\hline & Benign & 6 & $6.5 \%$ \\
\hline
\end{tabular}

\section{Postoperative complications}

Major postoperative complications after hepatobiliary pancreatic surgery included pancreatic fistula, biliary fistula, and bleeding. Only five patients had severe pancreatic fistula after operation. Three cases of biliary fistula occurred, one of which was severe. In addition, 2 of the 92 patients had postoperative bleeding and underwent emergency interventional embolization to return to stable condition. All details are shown in Table 4. 
Table 4

Perioperative outcomes of patients in our Department of Hepatobiliary and Pancreatic Surgical Oncology during February 2020

\begin{tabular}{|c|c|c|c|c|}
\hline & Male & Female & Total & P-value \\
\hline \multicolumn{5}{|c|}{ Pancreatic fistula $(n=44)$} \\
\hline BL & $24(72.8 \%)$ & $8(72.8 \%)$ & $32(72.8 \%)$ & \multirow[t]{3}{*}{1.000} \\
\hline B & $6(18.2 \%)$ & $2(18.2 \%)$ & $8(18.2 \%)$ & \\
\hline C & $3(9.1 \%)$ & $1(9.1 \%)$ & $4(9.1 \%)$ & \\
\hline \multicolumn{5}{|c|}{ Biliary fistula $(n=79)$} \\
\hline No & $56(96.6 \%)$ & $21(100.0 \%)$ & 77 (97.5\%) & \multirow[t]{2}{*}{1.000} \\
\hline Yes & $2(3.4 \%)$ & $0(0.0 \%)$ & $2(2.5 \%)$ & \\
\hline \multicolumn{5}{|c|}{ Bleeding $(n=92)$} \\
\hline No & $64(97.0 \%)$ & $26(100.0 \%)$ & $90(97.8 \%)$ & \multirow[t]{2}{*}{1.000} \\
\hline Yes & $2(3.0 \%)$ & $0(0.0 \%)$ & $2(2.2 \%)$ & \\
\hline
\end{tabular}

\section{Discussion}

In the space of just 3 months, a novel coronavirus - a family that historically was not viewed as a global health concern-has become daily headline news worldwide. Studies have shown that the disease, recently named COVID-19 (coronavirus disease 2019, COVID-19) by the World Health Organization (WHO), can induce symptoms including fever, dry cough, dyspnea, fatigue, and lymphopenia in infected patients. ${ }^{15,16}$ In more severe cases, infections cause viral pneumonia that can lead to SARS and even death. Since the first report of COVID-19 in December 2019 in Wuhan, China, the outbreak of the disease is has been continuously evolving. ${ }^{12,17}$ during the COVID-19 epidemic, many medical resources have been directed to infected patients and many hospitals have closed. As a result, patients with malignant tumors often lose their best treatment opportunities.

Hepatobiliary pancreatic tumors are one of the most common cancers. ${ }^{11,18}$ Patients with liver cancer, gallbladder cancer, or pancreatic cancer have a fast progression and poor prognosis. Our hepatobiliary pancreatic surgical oncology department performed 92 operations in February 1-29, 2020, during the most serious stage of the epidemic. In this study, we summarized the process management of patients with hepatobiliary pancreatic tumors during the outbreak, and clinical and surgical characteristics and postoperative complications in 92 patients. We believe that our experience will help other clinicians working during the epidemic.

Recent studies have reported that rapid person-to-person transmission of COVID-19 occurs. ${ }^{10,19,20}$ In addition, COVID-19 has been detected in stool samples of patients with abdominal symptoms. However, it 
is difficult to differentiate and screen patients with typical symptoms. Nevertheless, rapid human-tohuman transmission among close contacts is an important feature of the COVID-19 pneumonia. ${ }^{21}$ Hospitals in all provinces and cities across China have taken effective measures to control the spread of COVID-19. However, suspected or uninfected patients with malignant tumors have often been isolated, so these patients cannot receive timely and effective treatments, leading to tumor progression and more non-infectious deaths because of malignant tumors rather than COVID-19 infection. Our department of hepatobiliary and pancreatic surgical oncology was the only surgical oncology department that continued normal operations in the capital of China during the outbreak; we established a relatively reasonable admission process to ensure diagnosis and treatment of patients with malignant tumor in the surrounding area. In addition, we performed surgery in 92 patients from 12 provinces in the north of China during the COVID-19 epidemic. The above admission process from our department may be worth introducing in other large regional hospitals.

The advantages of minimally invasive surgery were demonstrated during the COVID-19 outbreak. ${ }^{22}$ Robotic surgical systems, which were developed to address the disadvantages of laparoscopy, have made minimally invasive hepatobiliary and pancreatic surgery much more accessible to surgeons. ${ }^{23,24}$ Among the 92 patients in this study, 93.5\% had malignant tumors, requiring timely and effective surgical resection, and $81.5 \%$ were subjected to robotic surgery and $2.2 \%$ to laparoscopic surgery. Moreover, our department led the drafting and development of an international expert consensus on robotic pancreatic and robotic hepatectomy surgery. ${ }^{25,26}$ Robotic surgery is as safe as laparoscopic and open surgery, with comparable intraoperative blood loss, length of hospital stay (LOS), overall postoperative complication rate, perioperative mortality, and rate of postoperative pancreatic fistula (POPF) to laparoscopic surgery. Moreover, robotic surgery has a longer operating time, less intraoperative blood loss, and shorter LOS than open surgery, whereas it has a similar overall complication rate, perioperative mortality, and POPF rate. ${ }^{25}$ Taken together, robotic surgery has some advantages in patients with hepatobiliary pancreatic tumor, especially during COVID-19 outbreak, in that it decreases LOS and enhances recovery after surgery.

The present study had some limitations. First, data came from a single center and were acquired retrospectively. Second, the study was descriptive, so it is unclear whether the results can be extrapolated to other public health events. Third, we only included patients who underwent emergency operations and elective surgeries for hepatobiliary and pancreatic cancers, so it remains to be confirmed whether the approach described is beneficial in patients with benign hepatobiliary and pancreatic diseases.

In conclusion, we performed surgical resection in 92 patients with hepatobiliary and pancreatic oncology in a department that maintained a normal working regimen during the COVID-19 epidemic. Our standardized hospitalization and treatment processes could prevent cross-infection of patients and still ensure the timely treatment of patients with hepatobiliary and pancreatic cancers. These findings will guide the operation of surgical oncology departments and treatment of patients with hepatobiliary and pancreatic cancers during serious epidemics. 


\section{Abbreviations}

$\mathrm{RBC}$

Red Blood Cell; WBC:White Blood Cell; CRP:C-reactive protein; ALT:Alanine Aminotransferase; AST:Aspartate Aminotransferase; CR:Creatinine; BUN:Blood Urea Nitrogen; BMI:Body Mass Index; PD:Pancreaticoduodenectomy ; RAMPS:Radical antegrade modular pancreatosplenectomy; Note

The test result of the patient with pneumonia was negative for the COVID-19;

\section{Declarations}

\section{Acknowledgements}

None

\section{Author contributions}

Conception and design: Rong Liu, Zhi-Ming Zhao, Xiu-Ping Zhang

Provision of study materials or patients: Xiang-Long Tan, Xuan Zhang, Ming-Gen Hu, Cheng-Gang Li, Yuan-Xing Gao, Guo-Dong Zhao

Collection and assembly of data: Zhi-Ming Zhao, Xiu-Ping Zhang, Shuai Xu

Data analysis and interpretation: Zhi-Ming Zhao, Xiu-Ping Zhang, Shuai Xu

Manuscript writing: Zhi-Ming Zhao, Xiu-Ping Zhang

Final approval of manuscript: All authors

\section{Funding}

None

\section{Availability of data and materials}

The datasets used or analyzed during the current study are available from the corresponding author on reasonable request

\section{Ethics approval and consent to participate}

All procedures performed in studies involving human participants were in accordance with the ethical standards of the institutional and/or national research committee and with the 1964 Helsinki declaration and its later amendments or comparable ethical standards. This study is approved by Ethics Committee of our hospital. 


\section{Consent for publication}

It is unavailable.

\section{Competing interests}

None

\section{References}

1. Huang C, Wang Y, Li X, et al. Clinical features of patients infected with 2019 novel coronavirus in Wuhan, China. Lancet. 2020;395(10223):497-506.

2. Ksiazek TG, Erdman D, Goldsmith CS, et al. A novel coronavirus associated with severe acute respiratory syndrome. N Engl J Med. 2003;348(20):1953-66.

3. Rota PA, Oberste MS, Monroe SS, et al. Characterization of a novel coronavirus associated with severe acute respiratory syndrome. Science. 2003;300(5624):1394-9.

4. de Groot RJ, Baker SC, Baric RS, et al. Middle East respiratory syndrome coronavirus (MERS-CoV): announcement of the Coronavirus Study Group. Journal of virology. 2013;87(14):7790-2.

5. Wu JT, Leung K, Leung GM. Nowcasting and forecasting the potential domestic and international spread of the COVID-19 outbreak originating in Wuhan, China: a modelling study. Lancet 2020.

6. Hui DS, Madani EIA. TA, et al. The continuing COVID-19 epidemic threat of novel coronaviruses to global health - The latest 2019 novel coronavirus outbreak in Wuhan, China. International journal of infectious diseases: IJID : official publication of the International Society for Infectious Diseases. 2020;91:264-6.

7. Bray F, Ferlay J, Soerjomataram I, Siegel RL, Torre LA, Jemal A. Global cancer statistics 2018: GLOBOCAN estimates of incidence and mortality worldwide for 36 cancers in 185 countries. Cancer J Clin. 2018;68(6):394-424.

8. Hu M, Liu Y, Li C, et al. Robotic versus laparoscopic liver resection in complex cases of left lateral sectionectomy. International journal of surgery. 2019;67:54-60.

9. Liu R, Zhang T, Zhao ZM, et al. The surgical outcomes of robot-assisted laparoscopic pancreaticoduodenectomy versus laparoscopic pancreaticoduodenectomy for periampullary neoplasms: a comparative study of a single center. Surgical endoscopy. 2017;31(6):2380-6.

10. Li Q, Guan X, Wu P, et al. Early Transmission Dynamics in Wuhan, China, of Novel CoronavirusInfected Pneumonia. The New England journal of medicine 2020.

11. Forner A, Reig M, Bruix J. Hepatocellular carcinoma. Lancet. 2018;391(10127):1301-14.

12. Chen N, Zhou M, Dong X, et al. Epidemiological and clinical characteristics of 99 cases of 2019 novel coronavirus pneumonia in Wuhan, China: a descriptive study. Lancet. 2020;395(10223):507-13.

13. Zhu N, Zhang D, Wang W, et al. A Novel Coronavirus from Patients with Pneumonia in China, 2019. N Engl J Med. 2020;382(8):727-33. 
14. Wang D, Hu B, Hu C, et al. Clinical Characteristics of 138 Hospitalized Patients With 2019 Novel Coronavirus-Infected Pneumonia in Wuhan, China. Jama 2020.

15. Zhang H. Early lessons from the frontline of the COVID-19 outbreak. Lancet. 2020;395(10225):687.

16. Wu JT, Leung K, Leung GM. Nowcasting and forecasting the potential domestic and international spread of the COVID-19 outbreak originating in Wuhan, China: a modelling study. Lancet. 2020;395(10225):689-97.

17. The L. Emerging understandings of COVID-19. Lancet. 2020;395(10221):311.

18. Zhang XP, Gao YZ, Chen ZH, et al. An Eastern Hepatobiliary Surgery Hospital/Portal Vein Tumor Thrombus Scoring System as an Aid to Decision Making on Hepatectomy for Hepatocellular Carcinoma Patients With Portal Vein Tumor Thrombus: A Multicenter Study. Hepatology 2018.

19. Li JY, You Z, Wang Q, et al. The epidemic of 2019-novel-coronavirus (COVID-19) pneumonia and insights for emerging infectious diseases in the future. Microbes infection. 2020;22(2):80-5.

20. Weston S, Frieman MB. COVID-19: Knowns, Unknowns, and Questions. mSphere 2020; 5(2).

21. Ahmad T, Hui J. One Health approach and Coronavirus Disease 2019. Human vaccines \& immunotherapeutics 2020: 1-2.

22. Wang ZZ, Tang WB, Hu MG, et al. Robotic vs laparoscopic hemihepatectomy: A comparative study from a single center. Journal of surgical oncology. 2019;120(4):646-53.

23. Montalti R, Scuderi V, Patriti A, Vivarelli M, Troisi RI. Robotic versus laparoscopic resections of posterosuperior segments of the liver: a propensity score-matched comparison. Surgical endoscopy. 2016;30(3):1004-13.

24. Choi GH, Chong JU, Han DH, Choi JS, Lee WJ. Robotic hepatectomy: the Korean experience and perspective. Hepatobiliary surgery nutrition. 2017;6(4):230-8.

25. Liu R, Wakabayashi G, Palanivelu C, et al. International consensus statement on robotic pancreatic surgery. Hepatobiliary surgery nutrition. 2019;8(4):345-60.

26. Liu R, Wakabayashi G, Kim HJ, et al. International consensus statement on robotic hepatectomy surgery in 2018. World journal of gastroenterology. 2019;25(12):1432-44.

\section{Figures}




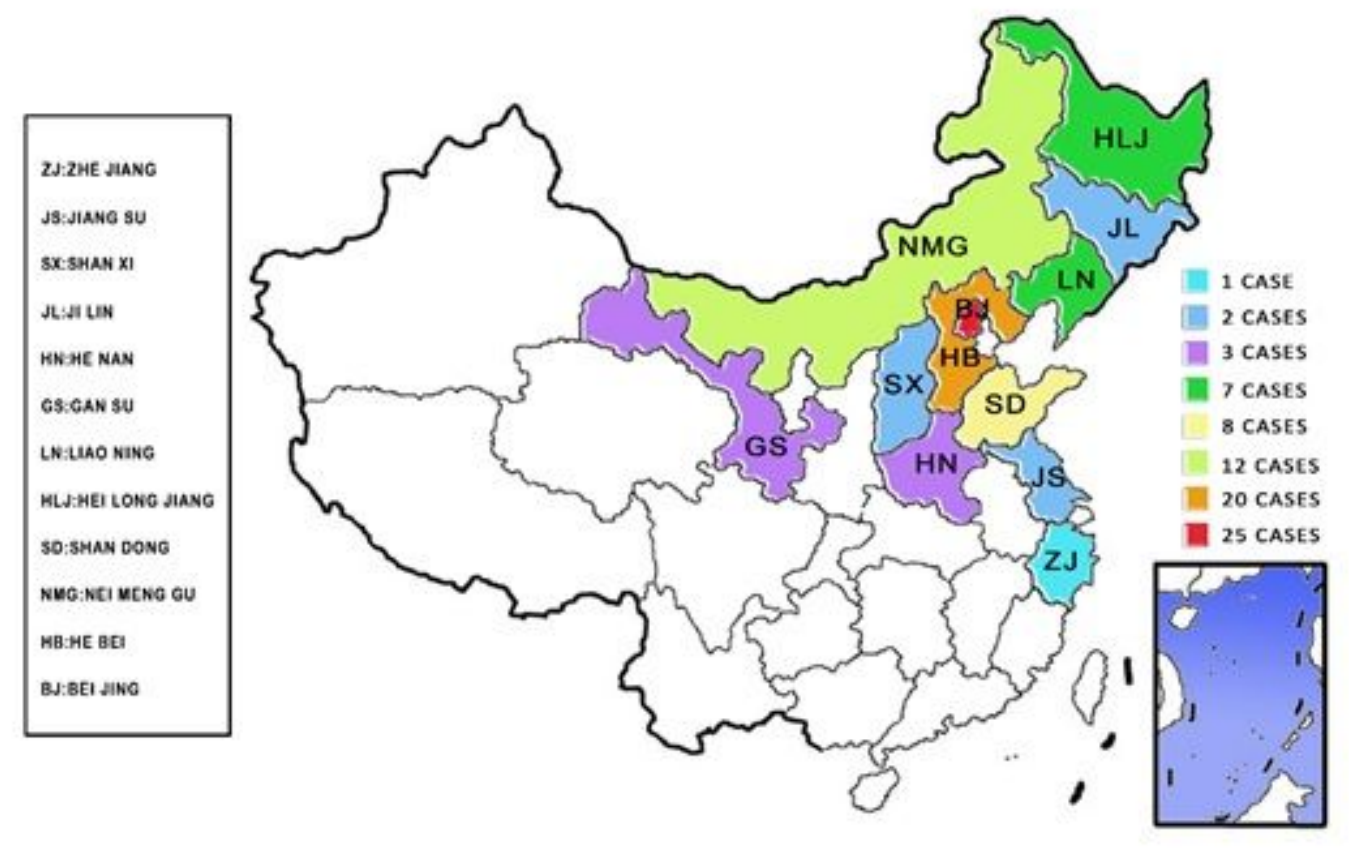

Figure 1

All 92 patients from 12 provinces in the north of China during the COVID-19 epidemic. Note: The designations employed and the presentation of the material on this map do not imply the expression of any opinion whatsoever on the part of Research Square concerning the legal status of any country, territory, city or area or of its authorities, or concerning the delimitation of its frontiers or boundaries. This map has been provided by the authors.

\begin{tabular}{|c|c|c|c|c|c|}
\hline \multicolumn{5}{|c|}{ Trends in disease types from 2017 to 2020} & \multirow[b]{2}{*}{$100.0 \%$} \\
\hline 160 & & & & & \\
\hline 140 & & & & & $90.0 \%$ \\
\hline 120 & 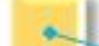 & & & & $80.0 \%$ \\
\hline 100 & & & & & 0000 \\
\hline 80 & & & & & $50.0 \%$ \\
\hline 60 & & & & & $40.0 \%$ \\
\hline 40 & & & & & $30.0 \%$ \\
\hline 20 & & & & & 1000 \\
\hline 0 & 2017 & 2018 & 2019 & 2020 & \multirow[t]{5}{*}{$0.0 \%$} \\
\hline Benign & 34 & 55 & 35 & 6 & \\
\hline Malignant & 97 & 95 & 117 & 86 & \\
\hline$\rightarrow-$ Malignant Ratio & $74.0 \%$ & $63.3 \%$ & $77.0 \%$ & $93.5 \%$ & \\
\hline$\longrightarrow$ Benign Ratio & $26.0 \%$ & $36.7 \%$ & $23.0 \%$ & $6.5 \%$ & \\
\hline
\end{tabular}


Figure 2

Trends in disease types from 2017 to 2020 in the same time period.

\begin{tabular}{|c|c|c|c|c|c|}
\hline \multicolumn{5}{|c|}{ Trends in surgical procedures from 2017 to 2020} & \multirow[b]{2}{*}{90.04} \\
\hline 160 & & & & & \\
\hline 140 & & & & & $80.0 \%$ \\
\hline 120 & & & & & $70.0 \%$ \\
\hline 100 & & & & & $60.0 \%$ \\
\hline 80 & & - & & 1 & $50.0 \%$ \\
\hline 60 & $\pi$ & & & & $40.0 \%$ \\
\hline 40 & & & & & $30.0 \%$ \\
\hline 20 & 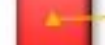 & & & & $20.0 \%$ \\
\hline 0 & & & & & $10.0 \%$ \\
\hline 0 & 2017 & 2018 & 2019 & 2020 & $0.0 \%$ \\
\hline$\Longrightarrow$ Open & 45 & 47 & 24 & 15 & \\
\hline —aparoscopic & 20 & 25 & 26 & 2 & \\
\hline$\Longrightarrow$ Robotic & 66 & 78 & 102 & 75 & \\
\hline$\rightarrow-$ Robotic Ratio & $50.4 \%$ & $52.0 \%$ & 67.1\% & $81.5 \%$ & \\
\hline - Laparoscopic Ratio & $15.3 \%$ & $16.7 \%$ & $17.1 \%$ & 2.26 & \\
\hline- Open Ratio & $34.4 \%$ & $31.3 \%$ & $15.8 \%$ & $16.3 \%$ & \\
\hline
\end{tabular}

\section{Figure 3}

Trends in surgical procedures from 2017 to 2020 in the same time period. 